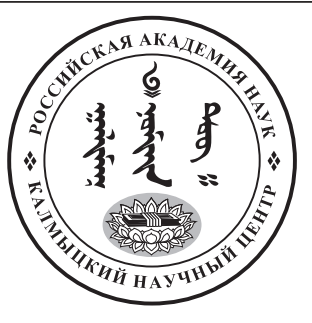

Published in the Russian Federation

Oriental Studies (Previous Name: Bulletin of the Kalmyk Institute

for Humanities of the Russian Academy of Sciences)

Has been issued as a journal since 2008

ISSN: 2619-0990; E-ISSN: 2619-1008

Vol. 13, Is. 1, pp. 198-207, 2020

DOI: $10.22162 / 2619-0990-2020-47-1-198-207$

Journal homepage: https://kigiran.elpub.ru

УДК 811.512.211

\title{
Эвенская лексикография: становление и современное состояние
}

\section{Сардана Ивановна Шарина ${ }^{1}$}

${ }^{1}$ Институт гуманитарных исследований и проблем малочисленных народов Севера СО РАН (д. 1, ул. Петровского, 677000 Якутск, Российская Федерация) кандидат филологических наук, ведущий научный сотрудник iD 0000-0002-7536-2757. E-mail: sarshar@mail.ru

(C) КалмНЦ РАН, 2020

(С) Шарина С. И., 2020

Аннотация. Введение. В условиях меняющегося мира теряется язык и значительный пласт устного народного творчества уникальных культур народов циркумполярной цивилизации. Для российской гуманитарной науки одним из приоритетных направлений остается документация языков, находящихся под угрозой исчезновения. Безотлагательной задачей является создание научной базы для ревитализации эвенского языка — создание различных типов словарей, описательных грамматик, издание фольклорных материалов. Цель. В статье дается краткий обзор лексикографических работ по эвенскому языку, начиная с накопления лингвистического материала в XVII - начале XVIII в. по настоящее время. Результатыл. В связи с необходимостью неотложной фиксации и документации эвенского языка, обосновывается необходимость разработки нового русско-эвенского словаря, предназначенного для широкого круга пользователей. Лексикографическое описание эвенского языка обусловлено не только отсутствием современных русско-эвенских словарей, но и наличием уникального фактического материала (полевого и архивного) по различным диалектам и говорам эвенского языка, характеризующего особенности реального функционирования языковых идиом. Отмечаются особенности содержания и структуры словаря. При составлении словарных статей ставится цель не только кодификации правил действующей орфографии, наиболее полного охвата эвенской лексики, характеристики грамматических признаков слова, но и подчеркивается важность учета культурологических факторов, которые отражают специфику материальной и духовной культуры народа. Особенностями составляемого словаря являются опора не только на литературный эвенский язык, но и учет диалектной лексики, максимально полное отражение всех разновидностей наименований, их функционирования через пометы и иллюстративные примеры. Будет разработан современный русско-эвенский словарь с учетом обширного диалектного материала, впервые вводимого в научный оборот. Важнейшим приложением результатов исследования в социально-экономической сфере явится его использование в области образования, науки, культуры, что будет способствовать возрождению, сохранению и развитию эвенского языка.

Ключевые слова: исчезающие языки, ревитализация, эвенский язык, лексикография, двуязычный словарь, кодификация правил орфографии, диалектная лексика, культурологический фактор 
Благодарность. Исследование проведено в рамках государственной субсидии - проект «Лексикология и лексикография языков коренных малочисленных народов Севера: этнокультурный аспект» (номер госрегистрации: АААА-А17-117020110014-0).

Для цитирования: Шарина С. И. Эвенская лексикография: становление и современное состояние // Oriental Studies. 2020. T. 13. № 1. С. 198-207. DOI: 10.22162/2619-0990-2020-47-1-198207

UDK 811.512 .211

\title{
Even Lexicography: Formation and Modern State
}

\section{Sardana I. Sharina ${ }^{1}$}

${ }^{1}$ Institute for Hunanities Reseach and Indigenous Studies of the North, Russian Academy of Sciences, Siberian Branch (1, Petrovsky St., Yakutsk 677000, Russian Federation)

Cand. Sc. (Philology), Leading Research Associate

iD 0000-0002-7536-2757. E-mail: sarshar@mail.ru

(C) KalmSC RAS, 2020

(C) Sharina S. I., 2020

\begin{abstract}
Introduction. Currently, despite the results achieved, the languages of the indigenous minorities of the North remain one of the little-studied. Scientific descriptions, insights, theoretical generalizations are required both by previously accumulated linguistic and folklore materials, and those that can be collected and preserved at the present time. The undelayable task is to create a scientific base for the revitalization of the Even language - the creation of various types of dictionaries, descriptive grammars, the publication of folklore materials. Object. The article provides a brief overview of lexicographical works on the Even language, starting with the accumulation of linguistic material in the seventeenth and early eighteenth centuries to the present. Results. Despite the fact that the tradition of compiling bilingual dictionaries in Even linguistics has a long history, the current state of this branch of lexicographical activity in historically established conditions does not meet the needs and requirements of modern society. In connection with the need for urgent fixing and documentation of the Even language, the necessity of developing a new Russian-Even dictionary designed for a wide range of users is justified. In the absence of dialect, spelling, etymological, cultural, encyclopedic, and other dictionaries of a minority language, lexicographers face broader tasks in compiling bilingual Even language dictionaries. One of them is the codification of the current spelling rules adopted in 1958. The next important task is the most comprehensive coverage of Even lexicon, a characteristic of the grammatical signs of a word. In the course of the lexicographic description of the Even language, a systematic study of the Even language vocabulary is carried out, which contributes to the presentation of an extensive dialectal material, first introduced into scientific circulation. Nevertheless the substance of compiling the Russian-Even dictionary is in the consideration of cultural factors that reflect the specificity of the material and spiritual culture of the people. The language represents all the specificity of the material and spiritual culture of the indigenous people of the North. Therefore, in a bilingual dictionary, which, first of all, satisfies the need of the user - non-native speaker of the language and culture in gaining knowledge, the background knowledge of the native speaker is reflected. Thus, a bilingual dictionary could become not only the result of the reflection of the culture of the people, but also an intermediator for the preservation and dissemination of lost traditional knowledge. The features of the compiled dictionary are not only reliance on the literary Even language, but also taking into account dialect vocabulary, the most complete reflection of all varieties of names, their functioning through marks and illustrative examples. A modern Russian-Even dictionary will be developed taking into account the extensive dialectal material first introduced into scientific circulation. The most important application of the results of research in the socio-economic sphere will be its use in the field of education, science, culture, which will contribute to the revival, preservation and development of the Even language.
\end{abstract}


Keywords: endangered languages, revitalization, the Even language, lexicography, bilingual dictionary, dialect vocabulary, cultural factor

Acknowledgements: Research was performed within a government subsidy - project name 'Lexicology and Lexicography of Indigenous Languages of the North: Ethnocultural Aspect' (State Reg. No. AAAA-A17-117020110014-0).

For citation: Sharina S. I. Even lexicography: Formation and Modern State. Oriental Studies. 2020. Vol. 13. No. 1. Pp. 198-207. (In Russ.). DOI: 10.22162/2619-0990-2020-47-1-198-207

\section{है}

\section{Введение}

Исследования исчезающих языков коренных малочисленных народов Севера дают возможность для дальнейшего их сохранения и развития, расширяют и углубляют научное представление о языковых системах в целом.

Эвенский (ламутский) язык относится к северно-тунгусской языковой общности, его изучение началось в XVII - начале XVIII в. Первые публикации материалов по лексическому составу эвенского языка состоялись в Амстердаме в 1692, 1705 и 1785 гг. благодаря голландскому ученому Н. Витсену (1641-1717). В 1719 г. были составлены списки ламутских слов немецким ученым Д. Г. Мессершмидтом (1685-1735), впоследствии опубликованные в 1823 г. в Париже Ю. Клапротом (1783-1835) [Петров 2013].

В материалах 1733-1741 гг. экспедиции В. И. Беринга (1681-1741) хранятся записи С. П. Крашенинникова (1711-1755), сделанные у ламутов Охотского побережья. В 1740-е гг. материалы по языкам и этнографии народов Восточной Сибири собирал Яков Линденау (1710-1795), они более 200 лет изучались в рукописях, но в 1983 г. были опубликованы с содержательными глоссариями [Линденау 1983].

В 1787 г. была опубликована работа академика П. С. Палласа (1741-1811) «Сравнительный словарь всех языков и наречий», включавшая наряду с материалами по языкам других народов, населявших Россию, и образцы двух диалектов языка эвенов [Бурыкин 1985]. К концу XVIII в. относятся словарные материалы М. М. Робека, изданные в 1811 г. в книге, посвященной экспедиции И. И. Биллингса (1758-1806) [Петров 2013].

В XIX в. начинается миссионерская деятельность Русской Православной Церкви по приобщению к вере инородцев. В этот период расширяется собирательская работа по эвенскому языку. Известно, что протоиерей Стефан Попов из Охотска, предположительно родной младший брат Преосвященного Иннокентия (Вениаминова), осуществил перевод на эвенский язык Евангелия (издан в 1880 г. в Казани). Он написал букварь, в котором излагались молитвы, и подготовил небольшой словарь [Краткий тунгусский словарь 1859], вышедший позже вторым изданием, очевидно, для нужд зарождающихся школ в эвенских приходах [Краткий тунгусский словарь 1900]. На основе языковых материалов, представленных в работах Стефана Попова, и словарей, текстов, собранных Г. Майделем (1835-1894), академиком А. Шифнером впервые были обобщены данные по эвенской грамматике [Schiefner 1873; Schiefner 1874], текстовые материалы недавно были заново подготовлены к печати и переизданы [Бурыкин 2007].

Благодаря неустанной деятельности ученого-языковеда и этнографа, Преосвященного Иннокентия (Вениаминова) (17971879) было переведено на эвенский язык Евангелие от Матфея [Краткий катихизис 1881].

Собственно первое систематическое научное описание грамматики и звукового строя эвенского языка было сделано В. Г. Богоразом (1865-1936) в конце XIX в. [Богораз 1931]. Его работа по материалам языка эвенов Колымы и Омолона ознаменовала следующую ступень и новый уровень в изучении эвенского языка и его диалектов (см. о нем: [Цинциус 1967]). Не все лексические материалы по эвенскому языку, собранные В. Г. Богоразом, опубликованы.

Изданный под авторством В. И. Левина в 1936 г. «Краткий эвенско-русский словарь», содержащий 5000 слов, оказался настолько совершенным и удобным для пользования, 
что в 2006 г. на Чукотке было организовано его переиздание в переработке на современную эвенскую графику [Левин 2006].

К концу 1920-х гг. усилиями ученых-этнографов и языковедов было собрано достаточно большое количество словарных материалов по отдельным тунгусо-маньчжурским языкам и диалектам. Это обстоятельство позволило приступить к сравнительно-историческому изучению тунгусо-манчжурских языков, к изучению сравнительно-исторической фонетики и лексики. К масштабным обобщениям лексики разных тунгусо-маньчжурских языков приступили практически одновременно два специалиста — тунгусо-маньчжуроведы С. М. Широкогоров (1887-1939), имевший огромный опыт полевой работы и к этому времени проживавший в эмиграции в Китае, и В. И. Цинциус (1903-1983), ученица В. Г. Богораза. В какой степени ученые были знакомы с результатами работ друг друга, мы не знаем, но С. М. Широкогоров с 1927 г. по 1932 г. состоял в переписке с В. М. Алексеевым, у которого В. И. Цинциус в это время обучалась английскому языку (см.: [Решетов 2003; Кузнецов 2012; Широкогоров 2016]).

Книга В. И. Цинциус «Сравнительная фонетика тунгусо-маньчжурских языков», к которой приложен сравнительный словарь, увидела свет в 1949 г. [Цинциус 1949]. «Тунгусский словарь» С. М. Широкогорова (об авторе см.: [Решетов 2003]) был издан в Токио в 1944 г. и выпущен вторым изданием в 1953 г. [Shirokogoroff 1944]. В основе этого словаря, как считается, лежат собственные записи С. М. Широкогорова, однако в него вошли многие известные материалы по другим тунгусо-маньчжурским языкам. Среди них - материалы по диалектам эвенского языка, собранные П. В. Олениным, собирателем музейных коллекций и участником нескольких полярных экспедиций (1868-1942). Собранные им материалы по эвенскому языку были переданы С. М. Широкогорову и вошли в его «Тунгусский словарь», о чем сказано в предисловии к первому изданию этого словаря, вышедшему в 1944 г. в Токио, что остается неизвестным подавляющему большинству исследователей эвенского языка. И в дальнейшем эти два издания оказались призванными на разную службу: В. И. Цинциус с коллективом единомышленников составила сводный «Сравнительный словарь тунгусо-маньчжурских языков» [Сравнительный словарь 1975-1977], задуманный авторами как основа Этимологического словаря алтайских языков, в то время как Словарь С. М. Широкогорова стал использоваться как материал, долженствующий свидетельствовать против теории родства алтайских языков. На его основе выполнен ряд работ, в основном переупорядочивающих материалы автора, относящиеся к территориям монголо-тунгусских контактов [Doerfer, Knüppel 2004; Knüppel 2012; Кнюппель 2015].

Огромный вклад в изучение эвенского языка внесла Вера Ивановна Цинциус (1903-1983), работы которой не утратили актуальности по сей день. Впервые в 1950 г. под её редакцией и авторством Л. Д. Ришес (1904-1971) был опубликован русско-эвенский словарь для школ (8500 слов) [Ришес 1950]. Через два года вышел в свет их совместный труд, уже расширенный и более ценный в научном плане - «Русско-эвенский словарь» (свыше 20000 слов) [Цинциус, Ришес 1952]. В 1957 г. они издали «Эвенско-русский словарь» (около 10000 слов) [Цинциус, Ришес 1957].

В дальнейшем в течение более трех десятилетий в эвенской лексикографии отмечается длительный перерыв. В 1988 г. впервые на действующей эвенской графике был опубликован двуязычный школьный словарь [Роббек, Дуткин, Бурыкин 1988]. Разработанный словарь стал частью проекта по обеспечению школ Севера словарями для начальной школы, в ходе которого был наработан полезный опыт лексикографической работы над словарями-минимумами [Бурыкин 1997]. В настоящее время имеется новое издание словаря для начальной школы объемом в 4500 слов [Петров, Федоренкова 2017], тематический эвенско-русский словарь [Кейметинова 2003] и опыт этнолингвистического словаря [Петров 2017].

В 2005 г. под авторством якутских ученых В. А. Роббека и М. Е. Роббек был опубликован «Эвенско-русский словарь» (более 14000 слов) [Роббек, Роббек 2005]. На сегодняшний день данный словарь является наиболее полным собранием эвенской лексики. Словарь содержит в основном материалы говоров восточного наречия, но включает и отдельные диалектизмы, относящиеся к западным говорам. 
Почти все исследователи грамматики, лексики и диалектологии эвенского языка в своих монографических работах приводят глоссарии рассматриваемых говоров и диалектов.

В настоящее время эвенский язык относится к исчезающим языкам. Об этом свидетельствуют данные переписей населения: в 1959 г. родным языком считали эвенский язык 77,5 \% эвенов, в 1989 г. — 43, 8 \%, в 2002 г. - 37,6 \%. Сегодня, по нашим данным, собранным во время экспедиционных работ в местах компактного проживания эвенов в разных регионах Российской Федерации, на родном языке разговаривают всего 16,5 \% представителей этноса. В данной ситуации перед научным сообществом стоит задача наиболее полного лингвистического обеспечения полноценного функционирования эвенского языка.

Задача лексикографической работы в эвенском языкознании - создание двуязычного словаря

Состояние современной двуязычной лексикографии в эвенском языкознании демонстрирует острую потребность в русско-эвенских словарях. В них нуждаются как люди, изучающие эвенский язык, так и сами носители языка, демонстрирующие разную степень владения родным языком.

Наиболее полный русско-эвенский словарь, изданный около 70 лет назад, во-первых, устарел (его словарный состав, ориентированный на 1940-е годы, страдает «милитаризированностью»), во-вторых, сегодня стал библиографической редкостью. Нужно подчеркнуть, что данный словарь вышел в свет еще до принятия в 1958 г. правил орфографии, т. е. не может использоваться для преподавания эвенского языка в школах, колледжах и вузах без коррекции написаний эвенских слов. На основе этого словаря немецкими лингвистами был издан эвенско-немецкий словарь [Doerfer, Hesche, Scheinhardt 1980], но в нем эвенские слова транслитерированы латиницей с графики названного выше словаря, так что он может использоваться только квалифицированными лингвистами.

Сотрудниками Института гуманитарных исследований и проблем малочисленных народов Севера СО РАН (далее ИГИиПМНС СО РАН) предпринимается попытка создания нового русско-эвенского словаря. Разработка русско-эвенского словаря - социальный заказ, он нужен и для носителей эвенского языка, которые в условиях билингвизма утрачивают свой язык, а с ним и часть культуры, и для тех изучающих эвенский язык (студенты, лингвисты, все желающие), для кого он не является родным. С учетом потребностей конечных пользователей на основе всех существующих русско-эвенских словарей разрабатывается новый двуязычный словарь. При этом расширена его содержательная часть за счет нового полевого и архивного материала по различным говорам и диалектам, усовершенствована формальная составляющая в соответствии с результатами современных исследований в области эвенской грамматики.

В отсутствие диалектных, орфографических, этимологических, культурологических, энциклопедических и других словарей миноритарного языка, при составлении двуязычных словарей эвенского языка перед лексикографами стоят более широкие задачи.

Одна из них - кодификация правил действующей орфографии эвенского языка, принятых в 1958 г. К сожалению, пока это реализовано только в виде монографии, ориентированной на специалистов по теории письма [Бурыкин 2004]. Еще с 70-х гг. $\mathrm{XX}$ в. в местах компактного проживания эвенов были распространены различные варианты письма, которые основывались на графике якутского, чукотского и корякского языков. Сегодня в Якутии некоторые специализированные учреждения и общественные объединения ставят вопрос о реформировании эвенской письменности, которое представляет собой изменение эвенского алфавита по образцу якутского. Вопрос о внесении кардинальных изменений в графику эвенского языка неоднократно получал отрицательную реакцию от научных центров, занимающихся сохранением и развитием эвенского языка. В ходе заседания Совета по языковой политике при Главе Республики Саха (Якутия) 31 августа 2015 г. специалисты ИГИиПМНС СО РАН, Института языков и культуры народов Северо-Востока Российской Федерации Северо-Восточного федерального университета (ИЯКН СВ РФ СВФУ) им. М. К. Аммосова оценили предлагаемую реформу 
как результат языковой интерференции и отметили нецелесообразность принятия подобных предложений. Неоспоримыми недостатками продвигаемой реформы алфавита и графики эвенского языка являются отсутствие системного изложения, а также отсутствие апробаций предлагаемой графики. Специалисты ведущих исследовательских центров Москвы и Санкт-Петербурга заключают, что вмешательство в систему эвенского письма в предлагаемом виде недопустимо, и выступают против катализации ассимилятивных процессов, вызванных эвенско-якутской фонетической и графической интерференцией. Они подчеркивают, с одной стороны, лингвистическую адекватность действующей орфографии, а с другой - ценность действующей графики как фактора, укрепляющего жизнеспособность эвенского языка и консолидирующего эвенский народ, разобщенный не только административным делением, но и диалектной раздробленностью. Современная эвенская письменность кодифицирована во множестве научных трудов исследователей, методической, лексикографической и художественной литературе на эвенском языке. Реформирование графики крайне опасно для исчезающего языка, так как может привести к нарушению преемственности культурной традиции эвенского народа.

Русско-эвенский словарь, кодифицирующий правила действующей орфографии эвенского языка, принятые в 1958 г., будет выполнять и функции орфографического словаря. К сожалению, на сегодня единственным русско-эвенским словарем, который дает написания слов в ныне действующей эвенской графике и орфографии, является только вышеуказанный «Словарь эвенско-русский и русско-эвенский», предназначенный для учащихся начальной школы [Роббек, Дуткин, Бурыкин 1988].

В разрабатываемом словаре дается и определенная характеристика грамматических признаков слова. В тех случаях, когда имеются особенности в образовании форм множественного числа эвенских существительных (в основном это - термины родства и свойства), они приводятся в словнике в скобках. Для всех глаголов неправильного спряжения и глаголов с основой на -н приводится форма 3-го лица единственного числа настоящего времени изъявительного наклонения. Для глаголов на конечные $\mu b$, $m$, д для выявления чередования согласных в скобках приводится форма 2-го лица единственного числа.

Важнейшая задача словаря - наиболее полный охват эвенской лексики. В данной связи в ходе лексикографического описания эвенского языка проводится систематическое изучение лексики эвенского языка, которое способствует представлению нового диалектного материала. Проводится анализ толкования некоторых терминов, исследование семантики определенных лексем. Добавляемые новые слова приводятся с указанием оттенков значений, например:

ПОРАЖЁННЫЙ 1. (удивленный) мянчича; 2. (побежденный) дабдача 3. (громом) агды херкатлан.

В разрабатываемом словаре впервые вводятся в научный оборот диалектизмы из говоров западного и среднего наречий, например:

КРОВЬ Хэсэ Ул.

ЛОДКА кэвкукэн Л., ульде $H-K$.

МОРЩИНИСТЫЙ лорини $H-K$.

ОСКОЛОК (кости от конечностей животных) часамна $T$., чахымды $M$.

ПЕЧКА дурутэк Л.

УКРАШЕНИЕ (оленьего седла) колат $B-K$.

СВЕРЛИТЬ эрэхэлэдэй Л.

СВЕРЛО эрэхэ Л.

СВИЯЗЬ пивчан $H-K$.

СКУПИТЬСЯ чирукаттай $C$., Л.

СЛУГА бэлтэлкэ Л.

ТАИТЬСЯ (прятаться) некисикладай, никисикладай $O x$.

ТАЛИСМАН эркэн $O x$.

ТРЁХКОПЫЛЬНАЯ ЮРТА илырдыка Д-Ч.

ТРУД хавна $H-K$.

ТРУХА куч Д-Ч.

ТУНДРА оввата Алл., өкрэ, өлкэрэ, улкэрэ $O x$. ТУРПАН кун 'аулгэ $H-K$.

УСТАТЬ обдудай Л., ачуладай $O x$., обдадай $O x$.

УСТАВАТЬ ургэттэй $O x .$, Л., обдудай Л., хэттэйи Д-Ч.

УСПЕХ дюбун $O x$.

УПОМЯНУТЫЙ эсип $O x$., урихип Л.

УМЕРШИЙ эдэрчэ Алл., $H-K$., аччоча Л., аччача Д-Ч.

УВАЖЕНИЕ төнкэн Л., хэрбынтын Д-Ч.

В ранее изданных словарях некоторые слова не переводились, были представлены 
русизмами, в разрабатываемом словнике они представлены бытующими в настоящее время в эвенском языке лексемами, напримep:

СВАДЬБА свадьба, торрикачак, курум

ТЕЛЕГРАММА телеграмма, мэтун дукун

ТЕЛЕЖКА ирудяк

ТЕПЛИЦА (оранжерея) нөчэв тэгудек Л.

ТОЧИЛЬЩИК авномно Л., агнамна $O x$, эмэрэлтэмуэ $O x$., өмөрөлтөмнэ Л.

ФАРШ фарш; мясной фарш учипча улрэ; рыбный фарш учипча олра

ФОТОАППАРАТ фотоаппарат, итивулдывун, аталалдывун

ФОТОГРАФИРОВАТЬ тилкукэндэй, тикукэндэй, аталдай, картыскала типкэндэй

Расширилась словарная статья определенных лексем с учетом полисемии, напримep:

СВИСТЕТЬ кекэдэй, кунидай, кунивкандай [нонан кунивкан-ни], куссаландай [ноуан кӯсалан-ни], кӯсалчидай; (o кулике) чиввектэй; (о тарбагане) пйсактай, чусактай; (о пуле, о ветре) кйнидай, кйуидай; свистеть через травинку титинукандай

СВЕТЛЫЙ 1. уэрин, / илан, иланьчи, отолка А; 2. (яркий) хутар; 3. (чистый, прозрачный) уөелдэне, уөелдэти, уөллдукэ

Не менее важной задачей при составлении русско-эвенского словаря нового поколения мы считаем учет культурологических факторов, которые отражают специфику материальной и духовной культуры народа. В языке репрезентируется вся специфика материальной и духовной культуры коренного малочисленного народа Севера. Поэтому в двуязычном словаре, который, прежде всего, удовлетворяет потребность пользователя - не-носителя языка и культуры в получении знания, отражены фоновые знания носителя языка. Таким образом, двуязычный словарь мог бы стать не только результатом отражения культуры народа, но и посредником по сохранению и распространению утрачиваемых традиционных знаний. Здесь интересны два сложных момента: выявление в материалах тех слов, которые ранее вообще не фиксировались словарями, и фиксация отражений средствами эвенского языка новых реалий, например, нейкэ ‘электричество’ (ранее «светильник», дэггөчимңээ ‘летчик’, кинамң̧а 'киномеханик' и др.)

Например, к слову нями, нямичан 'важенка' добавлены следующие лексемы: ора̄тu, оруху 'поздно телящаяся важенка', хонуун 'важенка с оленёнком'; тугэмэт 'только что отелившаяся важенка', хатти 'важенка 1-2 лет', маугай 'важенка неогуленная', көтөм 'бесплодная важенка'.

Слова, обозначающие понятие «ветер», - эдэн, эдни; (сильный, бурный) хунэ; (вихрь) дэву, хуги, —в словнике расширились лексемами: (пурга) куртэ, курэнэ; (внезапный, мимолетный) нэлэ; (меняющий направление) $x \bar{y} р \kappa a$; (ветер восточный) бургитлэ; (ветер западный) аткила; (ветер северный, холодный) идя; (ветер южный) няила; (со стороны северных ветров) дегилэгич/ дейилэгич; (ветер постоянный) куррэч; (ветер переменный) курги, кургилан.

К слову мо, мокан 'палка' добавлены следующие лексемы: хигритла 'палка, от которой строгают стружку'; хиняука 'палка для наполнения шерстью оленьих сёдел'; таралавун 'палка-тормоз при езде на нартах'; хораливки 'палочки для добывания огня'.

Переводимое в ранних изданиях только одной лексемой тэты слово «пальто» в словнике представляется более разнообразно:

ПАЛЬТО тэты; пальто женское из шкуры мехом наружу (надевается во второй половине осени) боласак; пальто из ровдуги женское летнее праздничное найми; пальто праздничное мужское из летней шкуры оленя мехом наружу о̆льми.

Результаты работы над словарем будут иметь прикладное значение для практики лексикографии (развитие опыта составления словарей и атласов), для разработки академической грамматики эвенского языка. Материалы и выводы статьи могут быть использованы при сравнительно-сопоставительных исследованиях, изучении опыта отечественной лексикографии для языков малочисленных народов РФ, при подготовке учебных пособий по эвенскому языку, диалектологии, в практике преподавания эвенского языка.

\section{Заключение}

В разные периоды эвенская лексикография была призвана решать ряд просветительских и культурных задач, каждая из 
которых была важна для своего времени. Уже самые ранние словари эвенского языка были призваны к использованию в обучении эвенской грамоте детей-эвенов в церковноприходских школах. В наши дни этот словарь решено переиздать как памятник культуры эвенов. Словари, изданные в 1930-1950-е гг., сослужили и служат прекрасную службу переводчикам художественной литературы и материалов для СМИ на эвенском языке. Эвенско-русские

\section{Сокращения}

Алл. - аллаиховский говор эвенского языка; В-К. - верхнеколымский говор; Д-Ч. - догдо-чебогалахский говор; Л. - ламунхинский говор; М. - момский говор; Н-К. - нижнеколымский говор; Ойм. - оймяконский говор; Ох. — охотский диалект; С. - саккырырский говор; Т. - томпонский говор; У-Я. - усть-янский говор; Ул. - ульинский говор.

\section{Литература}

Богораз 1931 - Богораз В. Г. Материалы по ламутскому языку// Тунгусский сборник. Выпуск 1. Л.: Изд-во АН СССР, 1931. С. 1-106. Бурыкин 1985 - Бурыкин А. А. Лингвистические материалы XVIII-XIX веков как источник изучения исторической диалектологии эвенского языка // Ареальные исследования в языкознании и этнографии. Тезисы Пятой конференции на тему «Проблемы атласной картографии». Уфа: Ротапринт БФАН СССР, 1985. С. 32-34.

Бурыкин 1997 - Бурыкин А А. Проблемы описания лексического состава языка и разработки словарей как учебных пособий в лексикографии языков народов Севера, Сибири, Дальнего Востока // Проблемы лексикографии. Сб. ст. СПб.: Изд-во Санкт-Петербургского университета, 1997. С. 152-162.

Бурыкин 2004 - Бурыкин А. А. Язык малочисленного народа в его письменной форме Социолингвистические и собственно лингвистические проблемы (на материале эвенского языка). СПб.: Петербургское востоковедение, 2004. 374 с.

Бурыкин 2007 - Бурыкин А. А. Первое собрание образцов фольклора эвенов Якутии (к 135-летию издания) // Acta Linguistica Petropolitana. Т. III. Ч. 3. СПб., 2007. С. 361392.

Кейметинова 2003 - Кейметинова А. Д. Эвенско-русский тематический словарь: Пособие и русско-эвенские словари, издающиеся с конца 1950-х гг., стали важным компонентом лингвистического описания эвенского языка, средством преподнесения его словарного состава для исследователей тунгусо-маньчжурских языков и алтайских языков в целом. Учет опыта издания словарей эвенского языка и подготовка новых изданий - это требование современного состояния лингвистической науки и залог ее успешного развития в будущем.

для учащихся нач. шк. СПб.: Просвещение. $2003.53 \mathrm{c}$.

Кнюппель 2015 - Кнюппель М. Лексико-статистические заметки о бурятских заимствованиях в тунгусо-маньчжурских языках: на основе материалов «Тунгусского словаря» С. М. Широкогорова // Acta Linguistica Petropolitana. Труды института лингвистических исследований. 2015. Т. 11. № 3. С. 227-232.

Краткий катихизис 1881 - Краткій катихизисъ, повседневныя молитвы и Евангеліе на Святую Пасху на Тунгусскомъ языкъ. Казань: Православ. миссионерск. о-во, типогр. Коковиной, 1881.64 с.

Краткий тунгусский словарь 1900 - Краткий тунгусский словарь. М.: Синод. тип., 1900. $33 \mathrm{c.}$

Краткий тунгусский словарь. 1859 - Краткий тунгусский словарь. М., В Синод. типографии, 1859. 32 с.

Кузнецов 2012 - Кузнецов А. М. Переписка В. М. Алексеева и С. М. Широкогорова // Известия Восточного института. 2012. Вып. 1. С. 119-133.

Левин 1936 - Левин В. И. Краткий эвенско-русский словарь: С прил. грамматического очерка / Научн.-исслед. ассоциация Ин-та Народов Севера им. П. Г. Смидовича Главсевморпути при СНК СССР. М.; Л.: Гос. учеб.-пед. изд-во, 1936. 224 с.

Левин 2006 - Левин В. И. Краткий эвенско-русский словарь. СПб.: ИПК Бионт, 2006. 247 с.

Линденау 1983 - Линденау Я. И. Описание народов Сибири (первая половина XVIII века). Магадан: Магаданск. кн. изд-во, 1983. 182 с.

Петров 2013 - Петров A. А. История изучения тунгусо-маньчжурских языков в России (очерки исследования). СПб.: Алмаз-Граф, $2013.88 \mathrm{c}$.

Петров 2017 - Петров А. А. Оленеводческая лексика эвенского языка. Этнолингвистиче- 
ский словарь. СПб.: РГПУ им. А. И. Герцена. 2017. 128 c.

Петров, Федоренкова 2017 - Петров А. А., Федоренкова В. С. Эвенско-русский и русскоэвенский словарь: около 4500 слов: учебное пособие. СПб.: Изд-во РГПУ им. А. И. Герцена. 2017. $204 \mathrm{c}$.

Решетов 2003 - Решетов А. М. С. М. Широкогоров: китайский период жизни и деятельности (1922-1939 гг.) // Зарубежная Россия 1917-1939. Кн. 2. СПб.: Европейский дом, 2003. C. $183-189$.

Ришес 1950 - Ришес Л. Д. Русско-эвенский словарь. Л.; М.: Учпедгиз, 1950. 259 с.

Роббек, Дуткин, Бурыкин 1988 - Роббек B. A., Дуткин Х. И., Бурыкин А. А. Эвенско-русский и русско-эвенский словарь. Л.: Просвещение, 1988. $263 \mathrm{c}$.

Роббек, Роббек 2005 - Роббек В. А., Роббек М. Е. Эвенско-русский словарь. Новосибирск: Наука, 2005. 356 с.

Сравнительный словарь 1975-1977 - Сравнительный словарь тунгусо-маньчжурских языков: Материалы к этимологическому словарю. Т. 1. Л.: Наука, 1975. 672 с. Т. 2. Л.: Наука, 1977. 472 c.

Цинциус 1949 - Цинщиус В. И. Сравнительная фонетика тунгусо-маньчжурских языков. Л.: Учпедгиз, 1949. 343 с.

Цинциус 1967 - Цинииус В. И. В. Г. Богораз-Тан как исследователь эвенского языка // Ученые записки Ленингр. гос. пед. ин-та им. А. И. Герцена. Т. 353. Л.: ЛГПИ, 1967. C. $90-95$.

Цинциус, Ришес 1952 - Цинииус В. И., Ришес Л. Д. Русско-эвенский словарь. М.:

\section{References}

[Comparative Dictionary of Tungus-Manchu Languages: Materials for an Etymological Dictionary]. Vol. 1. Leningrad: Nauka, 1975. 672 p. Vol. 2. Leningrad: Nauka, 1977. 472 p. (In Russ. and Manchu)

[Concise Dictionary of the Tungus Language]. Moscow: Synodal Publ. House, 1900. 33 p. (In Tung. and Russ.)

[Concise Dictionary of the Tungus Language]. Moscow: Synodal Publ. House, 1859. 32 p. (In Tung. and Russ.)

[Tungus-Language Brief Catechesis, Everyday Prayers, and Easter Gospel]. Kazan: Orthodox Christian Missionary; Kokovina, 1881. 64 p. (In Tung.)

Bogoraz V. G. Lamut (Even) language materials. In: [Tungus Collection]. Vol. 1. Leningrad:
Изд-во иностранных и национальных словарей, $1952.778 \mathrm{c}$.

Цинциус, Ришес 1957 - Цинииус В. И., Ришес Л. Д. Эвенско-русский словарь. Л.: Учпедгиз, 1957. $276 \mathrm{c}$.

Широкогоров 2016 - Широкогоров С. М. Письма к В. М. Алексееву. М.: Наука, Вост. лит., 2016. $134 \mathrm{c}$

Doerfer, Hesche, Scheinhardt 1980 - Doerfer Gerhard; Wolfram Hesche; Hartwig Scheinhardt: Lamutisches Wörterbuch. Wiesbaden: Harrassowitz, 1980. 1181 p.

Doerfer, Knüppel 2004 - Doerfer G., Knüppel $M$. Etymologisch-Ethnologisches Wörterbuch tungusischer Dialekte (vornehmlich der Mandschurei). Hildesheim; Zürich; New York: Georg Olms, 2004. 932 s.

Knüppel 2012 - Knüppel M. Sprachtabus in tungusischen Sprachen und Dialekten. Am Beispiel von S. M. Širokogorov's „Tungus Dictionary" (Tunguso-Sibirica 33). Wiesbaden, Harrassowitz, 2012. 131 p.

Schiefner 1873 - Schiefner A. Baron Gerhard von Maydell's Tungusische Sprachproben. Mitgeteilt von A. Schiefner // Bulletin de l'Academie imperiale des sciences de St. Petersbourg 20. 1875. Pp. 209-246. Melanges asiatiques 7.1873/76. Pp. 323-377

Schiefner 1874 - Schiefner A. Tungusische Miscellen. Von A. Schiefner. Bulletin de l'Academie imperiale des sciences de St. Petersbourg 20. 1874:2. Pp. 247-257. Melanges asiatiques 7. 1873/76. Pp. 378-394.

Shirokogoroff 1944 - Shirokogoroff S. M. A Tungus Dictionary. Tokyo, The Minzokugaku Kyokai, 1944. 256 p.

USSR Academy of Sciences, 1931. Pp. 1-106. (In Russ.)

Burykin A. A. [A Minority Language in Its Written Form: a Case Study of the Even Language. Sociolinguistic and Linguistic Aspects]. St. Petersburg: Peterburgskoe Vostokovedenie, 2004. 374 p. (In Russ.)

Burykin A. A. Even dialects: $18^{\text {th }}-19^{\text {th }}$ century linguistic materials as research sources. In: [Areal Studies in Linguistics and Ethnography]. Conf. proc. (Issues of Atlas Cartography). Ufa: Rotaprint, 1985. Pp. 32-34. (In Russ.)

Burykin A. A. Evens of Yakutia: the first collection of folklore patterns (celebrating the $135^{\text {th }}$ anniversary of publication). Acta Linguistica Petropolitana. 2007. Vol. III. No. 3. Pp. 361392. (In Russ.) 
Burykin A. A. Languages of the North, Siberia, and Far East: issues of vocabulary description and compilation of dictionaries as lexicographic manuals. In: [Issues of Lexicography]. Coll. papers. St. Petersburg: St. Petersburg State University, 1997. Pp. 152-162. (In Russ.)

Doerfer G., Knüppel M. [Etymological and Ethnological Dictionary of Tungusic Languages (Primarily Manchu Ones)]. Hildesheim; Zürich; New York: Georg Olms, 2004. 932 p. (In Germ. and Manchu)

Doerfer G., Wolfram H., Hartwig Sch. [Dictionary of the Lamut Language]. Wiesbaden: Harrassowitz, 1980. 1181 p. (In Germ. and Lam.)

Keymetinova A. D. [Even-Russian Topical Dictionary]. Manual for primary school students. St. Petersburg: Prosveshchenie, 2003. 53 p. (In Even and Russ.)

Knüppel M. [Language Taboos in Tungusic Languages and Dialects: a Case Study of S. Shirokogorov's Tungus Dictionary (TungusoSibirica 33)]. Wiesbaden: Harrassowitz, 2012. 131 p. (In Germ. and Tung.)

Knüppel M. Lexico-statistical remarks on Buryat loans in Tungus languages and dialects based on material from M. Shirokogorov's 'Tungus Dictionary'. Acta Linguistica Petropolitana. 2015. Vol. 11. No. 3. Pp. 227-232. (In Russ.)

Kuznetsov A. M. Correspondence between V. M. Alekseev and S. M. Shirokogorov. Oriental Institute Journal. 2012. No. 1. Pp. 119-133. (In Russ.)

Levin V. I. [Concise Even - Russian Dictionary: Supplemented with a Review of Even Grammar]. Smidovich Peoples of the North Research Association. Moscow; Leningrad: Uchpedgiz, 1936. 224 p. (In Even and Russ.)

Levin V. I. [Concise Even-Russian Dictionary]. St. Petersburg: Biont, 2006. 247 p. (In Even and Russ.)

Lindenau Ya. I. [Description of the Peoples of Siberia: Early to Mid-18 ${ }^{\text {th }}$ Century]. Magadan: Magadan Book Publ., 1983. 182 p. (In Russ.)

Petrov A. A. [Even Reindeer Breeding Vocabulary: Ethnolinguistic Dictionary]. St. Petersburg: Herzen State Pedagogical University of Russia, 2017. 128 p. (In Even and Russ.)

Petrov A. A. [History of Tungus-Manchu Linguistic Studies in Russia: Essays]. St. Petersburg: Almaz-Graf, 2013. 88 p. (In Russ.)
Petrov A. A., Fedorenkova V. S. [Even-Russian and Russian-Even Dictionary: Approx. 4500 Entries]. Student's manual. St. Petersburg: Herzen State Pedagogical University of Russia, 2017. 204 p. (In Even and Russ.)

Reshetov A. M. S. M. Shirokogorov: Chinese period of life and work, 1922-1939. In: [Russia Abroad: 1917-1939]. Vol. 2. St. Petersburg: Evropeyskiy Dom, 2003. Pp. 183-189. (In Russ.)

Rishes L. D. [Russian-Even Dictionary]. Leningrad, Moscow: Uchpedgiz. 1950. 259 p. (In Even and Russ.)

Robbek V. A., Dutkin Kh. I., Burykin A. A. [Even-Russian and Russian-Even Dictionary]. Leningrad: Prosveshchenie, 1988. 263 p. (In Even and Russ.)

Robbek V. A., Robbek M. E. [Even-Russian Dictionary]. Novosibirsk: Nauka, 2005. 356 p. (In Even and Russ.)

Schiefner A. Baron Gerhard von Maydell's Tungusic speech patterns delivered by A. Schiefner. Bulletin de l'Academie imperiale des sciences de St. Petersbourg. 1875. Vol. 20. Pp. 209-246. Melanges asiatiques. 1873/76. No. 7. Pp. 323-377. (In Germ.)

Schiefner A. Miscellaneous Tungusic materials submitted by A. Schiefner. Bulletin de l'Academie imperiale des sciences de St. Petersbourg 1874. Vol. 20. Part 2. Pp. 247-257. Melanges asiatiques. 1873/76. No. 7. Pp. 378394. (In Germ.)

Shirokogoroff S. M. A Tungus Dictionary. Tokyo: Minzokugaku Kyokai, 1944. 256 p. (In Tung. and Jap.)

Shirokogorov S. M. [Letters to V. M. Alekseev]. Moscow: Nauka, 2016. 134 p. (In Russ.)

Tsintsius V. I. [Comparative Phonetics of TungusManchu Languages]. Leningrad: Uchpedgiz, 1949. 343 p. (In Russ.)

Tsintsius V. I. V. Bogoraz-Tan as a researcher of the Even language. Uchenye zapiski Leningr. gos. ped. in-ta im. A. I. Gertsena. 1967. Vol. 353. Pp. 90-95. (In Russ.)

Tsintsius V. I., Rishes L. D. [Even-Russian Dictionary]. Leningrad: Uchpedgiz, 1957. 276 p. (In Even and Russ.)

Tsintsius V. I., Rishes L. D. [Russian-Even Dictionary]. Moscow: Foreign and national Dictionaries Publ., 1952. 778 p. (In Even and Russ.). 